\title{
Cognitive function of older adults engaging in physical activity
}

Monisha Ingold ${ }^{1}$, Nikki Tulliani ${ }^{1}$, Chetwyn C. H. Chan ${ }^{3,4}$ and Karen P. Y. Liu ${ }^{1,2^{*}}$ (D)

\begin{abstract}
Background: Physical activity can be classified as open-skilled or closed-skilled. Open-skilled physical activity, such as tennis, require participants to perform within a dynamic setting and respond to unpredictable and frequent environmental changes throughout the activity. Closed-skilled types of physical activity, such as swimming, are predictable and self-directed. However, the benefits of cognitive function in these two types of physical activities to older adults are unknown. This study examined the effects of participation in open- and closed-skilled physical activity on the cognitive function of older adults.

Methods: The study recruited a total of 61 participants aged 65 years and over. Participant recruitment was achieved by distributing flyers asking for volunteers in various sports venues. Participants self-reported to be without medical conditions affecting their physical and cognitive function. All participants underwent a two-hour assessment session involving the completion of seven standardised cognitive function assessments, which were used to assess a range of cognitive function.

Results: Overall mean scores across all of the assessments showed superior performance for the open- or closedskilled participants when compared with the no-physical-activity group. The results of 61 adults who participated in this study showed that closed-skilled physical activity was associated with better selective attention and visuospatial function while open-skilled physical activity was associated with better inhibition and cognitive flexibility function. No significant difference in self-regulation ability was found between the open- or closed-skilled groups.

Conclusions: Open-skilled physical activity was associated with better inhibition, visual tracking, and cognitive flexibility while closed-skilled physical activity was associated with better selective attention and visuospatial perception. The findings have important practical implications for the health and quality of life of ageing populations, knowing which particular types of physical activity might affect the cognitive function.
\end{abstract}

Keywords: Older adults, Physical activity, Cognitive function, Self-regulation

\section{Background}

As the ageing population is expected to almost triple by 2050 [1], there is a growing need for strategies to militate against common health issues associated with ageing to reduce the burden on the health system [2].

\footnotetext{
* Correspondence: karen.liu@westernsydney.edu.au

'School of Health Sciences, Western Sydney University, Locked Bag 1797, Penrith, NSW 2751, Australia

${ }^{2}$ Translation Health Research Institute, Western Sydney University, Locked Bag 1797, Penrith, NSW 2751, Australia

Full list of author information is available at the end of the article
}

While the ageing process is understood to alter people's cognitive function, with variability existing across both age and sex [3], regular participation in physical activity has been correlated with positive changes to brain structure and volume, such as an increase in white matter and parietal lobe gray matter volume [4] and hippocampal and basal ganglia volume $[5,6]$, and with improvement in a wide range of cognitive functioning skills in older adults [3, 7-12]. Physical activity is understood to promote cellular processes that influence the brain's neuroplasticity, particularly those processes involving the

(c) The Author(s). 2020 Open Access This article is licensed under a Creative Commons Attribution 4.0 International License which permits use, sharing, adaptation, distribution and reproduction in any medium or format, as long as you give appropriate credit to the original author(s) and the source, provide a link to the Creative Commons licence, and indicate if changes were made. The images or other third party material in this article are included in the article's Creative Commons licence, unless indicated otherwise in a credit line to the material. If material is not included in the article's Creative Commons licence and your intended use is not permitted by statutory regulation or exceeds the permitted use, you will need to obtain permission directly from the copyright holder. To view a copy of this licence, visit http://creativecommons.org/licenses/by/4.0/ The Creative Commons Public Domain Dedication waiver (http://creativecommons.org/publicdomain/zero/1.0/) applies to the data made available in this article, unless otherwise stated in a credit line to the data. 
synthesis of brain-derived neurotrophic factor (BDNF) in the hippocampus [13]. BDNF production provides a range of important functions for learning including neuronal and synaptic growth and differentiation, neuronal protection, and synaptic transmission $[13,14]$. As a result, participating in physical activity has been shown to provide protection against age-related cognitive function loss [e.g. [4-6, 15, 16].

One area of cognitive function that is known to decline as a consequence of the ageing process is executive function - the cognitive processes, primarily linked to the prefrontal cortex of the brain, which guide and regulate purposeful, goal-directed behaviour $[17,18]$. These cognitive processes include planning, interference control, dual-task coordination [17], shifting, updating, inhibition [18] and working memory [19], all of which play important roles in the performance of everyday functions from basic activities of daily living, such as grooming, through to more complex instrumental activities such as managing personal finances [20]. Each cognitive function serves a specific purpose but is used in combination with others to perform daily functions [21]. For example, effective dual-task coordination relies on both effective inhibitory function, which is the ability to suppress an irrelevant stimulus or inappropriate reaction, and working memory function, which is the temporary storing of information to be retrieved for learning and completing tasks [22]. Due to the significance of cognitive function processes in performing daily tasks, cognitive dysfunction can be associated with a decline in everyday functioning, which is particularly associated with age-related neurodegenerative diseases such as Alzheimer's disease [23].

One important goal-directed behaviour in the cognitive function is self-regulation. Self-regulation refers to the processes involved in managing thoughts, feelings, and behaviours [24]. These processes are essential for people's ability to demonstrate effective human behaviour [25] and include the capacity to plan, think flexibly, initiate appropriate behaviour, and inhibit inappropriate behaviour [26]. Self-regulation serves two key functions for effective daily functioning. Firstly, it helps people overcome challenges and achieve desired outcomes, such as the pursuit of long-term goals at the expense of short-term gratification [27]. Secondly, it is used for adapting goals in order to avoid consequences that may be psychologically distressing and protect an individual's sense of self by, for example, ignoring the impulse to carry out decisions that pose significant risk [28]. As unsuccessful implementation of self-regulatory behaviour poses a risk to effective daily functioning [27], it is an important area of focus as it affects older adults' quality of life and overall health [28].
Physical activity can be classified as open-skilled or closed-skilled [29]. Open-skilled physical activity, such as tennis, basketball, and fencing, requires participants to perform within a dynamic setting and respond to unpredictable and frequent environmental changes throughout the activity [30, 31]. In contrast, closedskilled types of physical activity, such as swimming, running, or yoga, are not dependent upon rapid changes in the environment and are instead predictable and selfdirected [31]. Both types of physical activity require selfregulation. However, while participation in open-skilled physical activity demands more cognitive effort from individuals because they must provide immediate responses to unpredictable environmental cues [17], closed-skilled physical activity demands attention on particular, often repetitive body movements for effective performance [32]. With the various forms and the need to interact with the environment in both open- and closed-skills physical activity, there are reports highlighting the association with memory [33] and especially object location memory [34]. While any specific benefits that closed-skilled as opposed to open-skilled physical activity may provide have not been identified, the vast majority of research has found there to be promising effects for a range of cognitive function from engagement in open-skilled physical activity [for example, [29, 35, $36]$. However, the literature is primarily limited to younger populations, particularly children [37-39] and young adults [31, 40-42], with one frequently cited study regarding middle-aged adults [43]. Although three studies have compared open- and closed-skilled physical activity in older populations, only the executive function subcomponents of inhibitory function [17], task-switching [30] and visuospatial working memory [44] have been investigated. Within the limited scope of these studies, it was found that due to open-skilled physical activity demanding more immediate responses than closed-skilled physical activity, open-skilled participants exhibited superior performance in the cognitive function under examination [17, 30, 44].

Additionally, while the association between physical activity and self-regulation function in older adults has been studied, the focus has been on the extent to which self-regulation acts as a determinant of older adults' maintenance of health and physical activity behaviours rather than on the effects of physical activity engagement on self-regulation functioning ability $[28,45-50]$. There is, therefore, a major role in our understanding of whether physical activity participation plays a role in supporting selfregulation functioning in older adults, potentially enabling greater daily functioning and quality of life, and whether the type of physical activity also has any significant role in this. 


\section{The present study}

This study intends to address these identified gaps in the literature by investigating the effects of open- versus closed-skilled physical activity on self-regulation and a wider variety of cognitive functions specifically among older people. The above-mentioned research underpins three hypotheses that were formulated for this study. Firstly, we expected to find better cognitive function in participants who engaged in either open- or closedskilled physical activity when compared with the nophysical activity participants. Secondly, we predicted there would be a greater effect on the cognitive function for the open-skilled group compared with both the closed-skilled and non-physical activity groups due to the apparent additional benefits from participating in these more cognitively-demanding types of physical activity [17, 30, 31, 42-44]. Finally, it was hypothesised that more frequent engagement in physical activity would positively impact the cognitive function of the open- and closed-skilled groups.

\section{Methods}

A quantitative, cross-sectional research design was implemented for this study.

\section{Participants}

A total of 61 community-dwelling older adults aged 64 to 87 (mean age $=71.93, \mathrm{SD}=5.50$ ) were recruited by convenience sampling method over a six-month period. Recruitment was conducted through flyers displayed in various sports venues in the greater Sydney region.

All reported being healthy without a medical history affecting their physical and cognitive function. Twenty-one engaged in open-skilled sports for at least $1 \mathrm{~h}$ per week for the previous year, 15 in closed-skilled sports, and 25 with no engagement in physical activity (Table 1). No

Table 1 Physical Activity Types $(N=61)$

\begin{tabular}{llll}
\hline & Type & Frequency & Percentage \\
\hline Open-Skilled $(n=21)$ & Golf & 9 & 14.8 \\
& Lawn Bowls & 9 & 14.8 \\
& Tennis & 2 & 3.3 \\
& Basketball & 1 & 1.6 \\
Closed-Skilled $(n=15)$ & Tai Chi & 4 & 6.6 \\
& Gym & 1 & 1.6 \\
& Line Dancing & 2 & 3.3 \\
& Walking & 4 & 6.6 \\
& Swimming & 3 & 4.9 \\
& Cycling & 1 & 1.6 \\
No Physical Activity $(n=26)$ & & 26 & 42.6 \\
& & 61 & 100 \\
\hline
\end{tabular}

significant difference in age $(P=.71)$, sex $(P=.59)$ and education level $(P=.90)$ was found among the three groups.

\section{Procedure}

Self-reported information was taken from all participants regarding demographic details, physical activity participation consisted of the type of activity and the number of years of engagement, as well as the total number of hours and sessions per week for each physical activity. Participants then underwent a $1-2 \mathrm{~h}$ session involving the completion of five standardised cognitive assessments and two self-regulation questionnaires. The study obtained ethical approval from the Western Sydney University Human Research Ethics Committee (approval number H11724).

\section{Measures}

The following standardised assessments were used to measure cognitive function.

\section{Repeatable battery for the assessment of neuropsychological status}

The immediate memory and delayed memory sections of the Repeatable Battery for the Assessment of Neuropsychological Status (RBANS) were administered in this study. This instrument has been used widely to detect and track the performance of a range of cognitive abilities in older adults [51].

\section{Trail making test - parts $a$ and $B$}

Both parts of the Trail Making Test measure processing speed, visual scanning, and mental flexibility through timing participants' ability to connect numbers from 1 to 25 (Trail Making A), and alternate between numbers and letters (Trail Making B) in ascending order [52]. Trail Making B is considered to have additional cognitive demands compared with Trail Making A $[11,53]$. Participants achieve a better performance score in both parts based on the shortest time it takes to complete the tasks. Therefore, a smaller number in their assessment score indicates better performance in the assessment.

\section{Benton Judgement of line orientation test}

The Benton Judgement of Line Orientation Test measures visuospatial perception. Participants are required to judge the distance between a pair of lines in relation to a diagram of 11 lines displayed in a semi-circle formation. The test has been used among a wide range of older adults [54] and is considered to have strong overall psychometric properties [55]. 


\section{Digit span forward and digit span backward}

The Digit Span Forward measures attention and processing speed while the Digit Span Backward measures working memory by, in both sections, asking participants to recall a sequence of digits in the correct order [56]. Sequences begin with two digits and extend by one number after each successful attempt by the participant. The number of digits successfully recalled by the participants was reported. The test is used extensively among a diverse range of populations, including older adults [57].

\section{Stroop color and word test}

The Stroop Color and Word Test is divided into three parts: Stroop (Word) [Stroop (W)], Stroop (Color) [Stroop (C)] and Stroop (Color and Word) [Stroop $(\mathrm{CW})]$ and measures information processing speed, selective attention and inhibition by requiring participants to read words and name colours as rapidly and correctly as possible within $45 \mathrm{~s}$ [58]. Within the task, participants must ignore the written colour word and state the colour of the ink, which requires them to simultaneously ignore some information while selectively attending to target information. As a result, it is considered to be an effective measure of attention and has been used extensively in older populations [8]. Only the T-scores of the assessment were analysed and reported in this study.

\section{Self-regulation questionnaire}

The Self-Regulation Questionnaire (SRQ) is a selfreporting tool containing 63 items on a 5-point Likert scale, which measures seven areas of self-regulation: receiving relevant information, evaluating the information, triggering change, searching for options, formulating a plan, implementing a plan and assessing a plan's effectiveness. Instead of being domain-specific, this instrument measures general self-regulation ability and has been used extensively with adult populations [59].

\section{Self-regulation of learning self-report scale}

The Self-Regulation of Learning Self-Report Scale (SRLSRS) is a self-reporting assessment tool containing 50 items. It measures the areas of planning, self-monitoring, evaluation, reflection, effort, and self-efficacy within multiple learning domains [60].

\section{Data analysis}

Descriptive statistics on the demographic data and the results of the seven standardised assessments were analysed. Pearson correlations were used to assess the relationship between the cognitive function measures in the open-skilled, closed-skilled, and no physical activity participation groups, and between assessment results and participations in physical activity. The Multivariate Analysis of Variance (MANOVA) was used to explore the differences in cognitive function between the three participant groups. Multivariate Analysis of Co-Variance (MANCOVA) was used with age and sex as covariates in the analysis because the variance in cognitive function measures has been detected among different older agegroups [61] and between men and women [3]. Further analysis in the cognitive function measures between the participants in the open- and closed-skilled physical activity groups was completed using MANCOVA with age, sex, and participation in physical activity as covariates.

\section{Results}

Table 1 shows the distribution of physical activity types from the open- and closed-skilled groups. The most common types of physical activity among the openskilled group were golf $(n=9)$ and lawn bowls $(n=9)$ while Tai Chi $(n=4)$, walking $(n=4)$ and swimming $(n=3)$ were the most common types of physical activity among the closed-skilled group.

The demographics and mean scores of the three participant groups' physical activity participation and standardised assessments are presented in Table 2. The mean age of the open-skilled group $(M=71.52, S D=$ 6.23), closed-skilled group $(M=71.33, S D=5.19)$ and non-physical activity group $(M=72.64, S D=5.16)$ were similar $(P=.71)$. The open-skilled group $(M=17.16$, $S D=16.94$ ) had spent more years engaging in physical activity than the closed-skilled group $(M=12.27, S D=$ 12.15) but no significant difference was found $(P=.22)$. The open-skilled group engaged in significantly more hours of physical activity per week $(M=3.33, S D=1.23)$ than the closed-skilled group $(M=1.00, \quad S D=.46)$ $(P=.001)$. However, the closed-skilled group $(M=3.36$, $S D=1.98)$ engaged in significantly more sessions per week than the open-skilled group $(M=1.76, S D=.89)$ $(P<.001)$.

By reviewing the raw scores of the cognitive function between the open-skilled and closed-skilled groups (Table 2), the open-skilled group achieved better results in the RBANS Delayed Memory, Trail Making A, Trail Making B, Digit Span Backward, Stroop (W), Stroop $(C W)$, the SRL-SRS components of Planning, SelfMonitoring, and Evaluation and the Self-Regulation Questionnaire (SRQ). However, the closed-skilled group performed more effectively in the RBANS Immediate Memory Index Score, the Benton Judgement of Line Orientation, Digit Span Forward, Stroop (C), and the SRL-SRS components of Reflection, Effort, and SelfEfficacy. The 'no physical activity' group did not achieve any mean scores that were better than either the openor closed-skilled groups for any of the assessments.

When reviewing participants' physical activity engagement (hours per week, sessions per week and years of participation), significant correlations $(P<.05)$ were 
Table 2 Demographics Information and Assessment Results

\begin{tabular}{|c|c|c|c|c|c|c|c|c|}
\hline & \multicolumn{2}{|c|}{$\begin{array}{l}\text { Open-skilled }(n=21 ; \\
\text { Female }=9 ; \text { Male }=12)\end{array}$} & \multicolumn{2}{|c|}{$\begin{array}{l}\text { Closed-skilled }(n=15 ; \\
\text { Female }=9 ; \text { Male }=6)\end{array}$} & \multicolumn{2}{|c|}{$\begin{array}{l}\text { No physical activity } \\
(n=25 ; \text { Female }=12 ; \text { Male }=13)\end{array}$} & \multicolumn{2}{|c|}{$\begin{array}{l}\text { Total Sample }(n=61 ; \\
\text { Female = 30; Male = 31) }\end{array}$} \\
\hline & Mean (SD) & Range & Mean (SD) & Range & Mean (SD) & Range & Mean (SD) & Range \\
\hline$\overline{\text { Age }}$ & $71.52(6.23)$ & $65-87$ & $\begin{array}{l}71.33 \\
(5.19)\end{array}$ & $64-83$ & $72.64(5.16)$ & $65-84$ & $\begin{array}{l}71.93 \\
(5.50)\end{array}$ & $64-87$ \\
\hline Physical activity participation (years) & $\begin{array}{l}17.16 \\
(16.94)\end{array}$ & $1-53$ & $\begin{array}{l}12.27 \\
(12.15)\end{array}$ & $0-37$ & & & $\begin{array}{l}8.93 \\
(13.78)\end{array}$ & $0-53$ \\
\hline $\begin{array}{l}\text { Duration of Physical Activity Session } \\
\text { (hours/week) }\end{array}$ & $3.33(1.23)$ & $1-5$ & $1.00(.46)$ & $0-2$ & & & $1.39(1.65)$ & $0-5$ \\
\hline $\begin{array}{l}\text { Frequency of Physical Activity } \\
\text { (sessions/week) }\end{array}$ & $1.76(.89)$ & $1-4$ & $3.36(1.98)$ & $0-7$ & & & $1.40(1.71)$ & $0-7$ \\
\hline RBANS IM Index Score & $\begin{array}{l}92.43 \\
(17.45)\end{array}$ & $\begin{array}{l}65.00- \\
126.00\end{array}$ & $\begin{array}{l}\mathbf{9 6 . 4 7} \\
(13.23)\end{array}$ & $\begin{array}{l}78.00- \\
120.00\end{array}$ & $91.00(16.12)$ & $53.00-114.00$ & $\begin{array}{l}92.84 \\
(15.85)\end{array}$ & $\begin{array}{l}53.00- \\
126.00\end{array}$ \\
\hline RBANS DM Index Score & $\begin{array}{l}95.33 \\
(12.93)\end{array}$ & $\begin{array}{l}60.00- \\
110.00\end{array}$ & $\begin{array}{l}92.73 \\
(14.25)\end{array}$ & $\begin{array}{l}64.00- \\
112.00\end{array}$ & $95.16(12.51)$ & $60.00-116.00$ & $\begin{array}{l}94.62 \\
(12.92)\end{array}$ & $\begin{array}{l}60.00- \\
116.00\end{array}$ \\
\hline Trail Making A & $\begin{array}{l}31.69 \wedge \\
(10.51)\end{array}$ & $\begin{array}{l}19.10- \\
67.48\end{array}$ & $\begin{array}{l}33.58 \\
(12.26)\end{array}$ & $\begin{array}{l}16.80- \\
65.10\end{array}$ & $35.60(11.26)$ & $20.68-63.07$ & $\begin{array}{l}33.76 \\
(11.20)\end{array}$ & $16.80-67.48$ \\
\hline Trail Making B & $\begin{array}{l}72.09 \wedge \\
(25.43)\end{array}$ & $\begin{array}{l}33.30- \\
142.22\end{array}$ & $\begin{array}{l}72.47 \\
(24.97)\end{array}$ & $\begin{array}{l}31.15- \\
123.00\end{array}$ & $86.58(28.28)$ & $40.34-169.26$ & $\begin{array}{l}78.12 \\
(27.04)\end{array}$ & $\begin{array}{l}31.15- \\
169.26\end{array}$ \\
\hline Benton Judgement of Line Orientation & $20.05(7.12)$ & $\begin{array}{l}13.00- \\
30.00\end{array}$ & $\begin{array}{l}\mathbf{2 2 . 6 0} \\
(6.80)\end{array}$ & $\begin{array}{l}13.00- \\
30.00\end{array}$ & $15.12(3.56)$ & $11.00-26.00$ & $\begin{array}{l}18.65 \\
(6.52)\end{array}$ & $11.00-30.00$ \\
\hline Digit Span Forward & $5.81(1.86)$ & $3.00-10.00$ & $6.33(1.54)$ & $3.00-8.00$ & $5.28(1.31)$ & $3.00-7.00$ & $5.72(1.60)$ & $3.00-10.00$ \\
\hline Digit Span Backward & $4.38(1.28)$ & $2.00-7.00$ & $4.20(1.01)$ & $3.00-6.00$ & $3.92(1.22)$ & $2.00-7.00$ & $4.15(1.19)$ & $2.00-7.00$ \\
\hline Stroop (W) T-Scores & $\begin{array}{l}\mathbf{5 0 . 3 3} \\
(8.14)\end{array}$ & $\begin{array}{l}35.00- \\
66.00\end{array}$ & $\begin{array}{l}44.20 \\
(9.46)\end{array}$ & $\begin{array}{l}28.00- \\
62.00\end{array}$ & $42.76(14.78)$ & $4.00-69.00$ & $\begin{array}{l}45.72 \\
(11.92)\end{array}$ & $4.00-69.00$ \\
\hline Stroop (C) T-Scores & $\begin{array}{l}39.05 \\
(13.84)\end{array}$ & $\begin{array}{l}-2.00- \\
59.00\end{array}$ & $\begin{array}{l}\mathbf{4 3 . 9 3} \\
(10.60)\end{array}$ & $\begin{array}{l}20.00- \\
62.00\end{array}$ & $31.00(19.43)$ & $-16.00-53.00$ & $\begin{array}{l}36.95 \\
(16.42)\end{array}$ & $\begin{array}{l}-16.00- \\
62.00\end{array}$ \\
\hline Stroop (CW) T-Scores & $\begin{array}{l}\mathbf{5 2 . 9 5} \\
(8.83)\end{array}$ & $\begin{array}{l}40.00- \\
71.00\end{array}$ & $\begin{array}{l}47.80 \\
(9.49)\end{array}$ & $\begin{array}{l}30.00- \\
71.00\end{array}$ & $45.68(7.64)$ & $34.00-62.00$ & $\begin{array}{l}48.70 \\
(8.98)\end{array}$ & $30.00-71.00$ \\
\hline SRL-SRS-Planning & $\begin{array}{l}29.57 \\
(4.64)\end{array}$ & $\begin{array}{l}18.00- \\
37.00\end{array}$ & $\begin{array}{l}28.33 \\
(6.41)\end{array}$ & $\begin{array}{l}10.00- \\
35.00\end{array}$ & $27.88(7.12)$ & $14.00-46.00$ & $\begin{array}{l}28.57 \\
(6.13)\end{array}$ & $10.00-46.00$ \\
\hline SRL-SRS-Self-Monitoring & $\begin{array}{l}26.81 \\
(4.35)\end{array}$ & $\begin{array}{l}14.00- \\
32.00\end{array}$ & $\begin{array}{l}25.60 \\
(4.08)\end{array}$ & $\begin{array}{l}15.00- \\
32.00\end{array}$ & $24.60(5.40)$ & $12.00-36.00$ & $\begin{array}{l}25.61 \\
(4.77)\end{array}$ & $12.00-36.00$ \\
\hline SRL-SRS-Evaluation & $\begin{array}{l}33.48 \\
(4.07)\end{array}$ & $\begin{array}{l}27.00- \\
40.00\end{array}$ & $\begin{array}{l}31.33 \\
(6.14)\end{array}$ & $\begin{array}{l}22.00- \\
40.00\end{array}$ & $30.08(6.20)$ & $14.00-40.00$ & $\begin{array}{l}31.56 \\
(5.65)\end{array}$ & $14.00-40.00$ \\
\hline SRL-SRS-Reflection & $17.38(6.87)$ & $0-24.00$ & $\begin{array}{l}17.67 \\
(6.36)\end{array}$ & $\begin{array}{l}7.00- \\
25.00\end{array}$ & $15.20(5.29)$ & $5.00-23.00$ & $\begin{array}{l}16.56 \\
(6.14)\end{array}$ & $0-25.00$ \\
\hline SRL-SRS-Effort & $32.14(9.20)$ & $0-40.00$ & $\begin{array}{l}32.67 \\
(4.27)\end{array}$ & $\begin{array}{l}25.00- \\
40.00\end{array}$ & $29.64(6.62)$ & $13.00-40.00$ & $\begin{array}{l}31.24 \\
(7.20)\end{array}$ & $0-40.00$ \\
\hline SRL-SRS-Self-Efficacy & $30.62(8.29)$ & $0-39.00$ & $\begin{array}{l}\mathbf{3 1 . 7 3} \\
(4.33)\end{array}$ & $\begin{array}{l}26.00- \\
40.00\end{array}$ & $28.24(6.35)$ & $8.00-37.00$ & $\begin{array}{l}29.92 \\
(6.75)\end{array}$ & $0-40.00$ \\
\hline SRQ & $\begin{array}{l}\mathbf{2 2 8 . 6 2} \\
(19.99)\end{array}$ & $\begin{array}{l}182.00- \\
280.00\end{array}$ & $\begin{array}{l}213.80 \\
(60.61)\end{array}$ & $0-260.00$ & $216.04(22.65)$ & $157.00-258.00$ & $\begin{array}{l}219.82 \\
(35.18)\end{array}$ & $0-280.00$ \\
\hline
\end{tabular}

Highest mean scores in bold. 95\% Confidence Interval for Mean, SD standard deviation, $\wedge$ lower score indicates better cognitive score RBANS IM Repeatable Battery for the Assessment of Neuropsychological Status: Immediate Memory, RBANS DM Repeatable Battery for the Assessment of Neuropsychological Status: Delayed Memory, (W) Word, (C) Colour, (CW) Colour-Word, SRL-SRS Self-Regulation of Learning Self-Report Scale, SRQ Self-Regulation Questionnaire

found between hours of physical activity engagement per week and cognitive function measures for the Benton Judgement of Line Orientation (visuospatial perception) $(r=.28, P=.03)$, Digit Span Backward (working memory) $(r=.31, P=.02)$, Stroop (W) (information processing and attention) $(r=.29, P=.03)$ and Stroop (CW) (selective attention and inhibition) $(r=.38, P=.003)$ (Table 3$)$.
The number of years participants engaged in physical activity was significantly correlated with results from the Benton Judgement of Line Orientation $(r=.44, P<.001)$ and the Stroop (W) $(r=.32, P=.01)$. The frequency of physical activity participation per week was significantly correlated with scores from the Benton Judgement of Line Orientation $(r=.40, P=.001)$, the Digit Span 


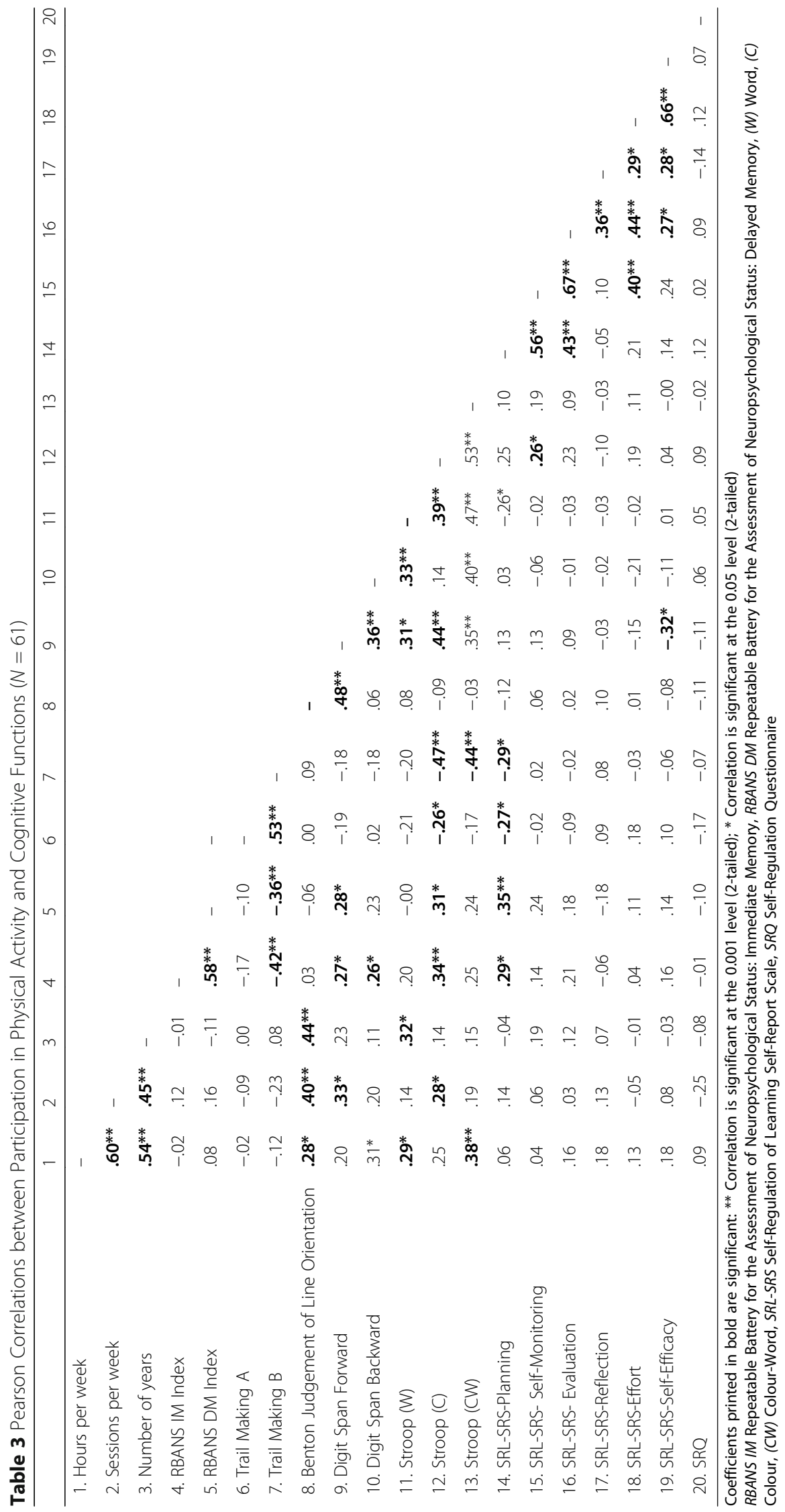


Forward (attention and processing speed) $(r=.33$, $P=.01)$ and Stroop $(C)(r=.28, P=.03)$.

The results of MANOVA comparing the results of the three groups showed a significant difference between the open-skilled, closed-skilled, and no physical activity participation groups for cognitive function assessment scores $\left[F(34,82)=2.14, P=.003\right.$; partial $\eta^{2}=.46$ ) (Table 4). Statistically significant mean scores were observed for the Benton Judgement of Line Orientation $(P=.001)$, Stroop (C) $(P<.05)$, and Stroop $(C W)(P<.05)$. Significant better results $(P<.05)$ were detected in the open-skilled physical activity group when compared with the no physical activity group in the Benton Judgement of Line Orientation, Stroop (CW), Stroop (W), SRL-SRS (Evaluation) and borderline significance $(P=.070)$ was found for Trail Making B. Significant better results were detected in the closedskilled when compared with the no physical activity groups for the Benton Judgement of Line Orientation $(P<.001)$, Stroop $(C)(P<.05)$ and Digit Span Forward $(P<.05)$. There was borderline significance $(P=.079)$ in Stroop (CW) between the open- and closed-skilled groups. No significant results were found for any of the other assessments.

The results of MANCOVA showed a significant overall effect when adjusted for age $[F(34,82)=2.11$, $P=.003$; partial $\left.\eta^{2}=.47\right]$; adjusted for sex $[\mathrm{F}(34,82)=$ 2.21, $P=.002$; partial $\left.\eta^{2}=.48\right]$ and adjusted for both age and sex $\left[\mathrm{F}(34,80)=2.18, P=.002\right.$; partial $\left.\eta^{2}=.48\right]($ Table 4). Adjusting for the possible differences in either age or sex, significant findings for Trail Making B, Benton Judgement of Line Orientation Scores, Stroop (C) and Stroop (CW) were found among the three groups. When adjusted for age, significant differences were found between open-skilled and no physical activity groups in Benton Judgement of Line Orientation $(P=.004)$ and Stroop $(C)(P=.007)$, and between closed-skilled and no physical activity groups in Benton Judgement of Line Orientation $(P<.001)$ and Stroop $(C)(P=.021)$. When adjusted for sex, significant differences were found between open-skilled and no physical activity groups in Trail Making B $(P=.001)$, Benton Judgement of Line Orientation $(P=.006)$ and Stroop $(C W)(P=.005)$, and between closed-skilled and no physical activity groups in Benton Judgement of Line Orientation $(P<.001)$, Digit Span Forward $(P=.038)$ and Stroop $(C)(P=.020)$. However, when both age and sex controls were used together, only borderline significant $(P=.058)$ was found in Stroop $(\mathrm{CW})$ between the open-skilled and no physical activity groups. Similar between-group differences $(P<.05)$ were observed in all other cognitive functions when adjusted for age and sex as compared with the results when adjusted for age only. The between-group differences among open-skilled and no physical activity groups for Stroop $(C)(P=.078)$ and between-group differences regarding closed-skilled and open-skilled groups for Stroop $(\mathrm{CW})(P=.068)$ were only borderline significant when controlled for sex, and not significant when age and sex controls were used together.

When comparing the cognitive function of participants in the open- and closed-skilled physical activity group, the results of MANCOVA showed a non-significant overall effect when adjusted for age, sex and participation in physical activity $[\mathrm{F}(17,11)=.857, P=.624$; partial $\left.\eta^{2}=.57\right]$ (Table 5). Significant differences were found between open- and closed-skilled physical activity groups in Trail Making B $(P=.044)$, Stroop (W) $(P=.019)$ and Stroop $(C)(P=.045)$. Participants in the open-skilled physical activity group had better results in Trail Making B and Stroop (W), while those in the closed-skilled physical activity group had a better result in Stroop (C).

\section{Discussion}

The purpose of this cross-sectional study was to understand how engagement in open- and closed-skilled forms of physical activity affect the cognitive function of older adults. Findings from this study suggest that physical activity, in both open- and closed-skilled forms, and a higher level of participation intensity and frequency, may be beneficial for specific cognitive function in older adults.

While not all results were significant, in accordance with our first hypothesis, overall mean scores across each of the cognitive function assessments showed a better performance for either the open- or closed-skilled participants compared with the no-physical activity group. Significant between-group differences for visuospatial perception, processing speed, selective attention, inhibition and self-regulation of evaluation were found between either the open-skilled and no physical activity groups, or closed-skilled and no physical activity groups, adding further to the large body of evidence showing better cognitive function ability for older adults who participate in physical activity compared with those who do not $[3,4,8,11,17,30,62,63]$.

Results showed that, in comparison to closed-skilled and non-physical activity, open-skilled physical activity was associated with significantly better selective attention and inhibition skills (Stroop $(\mathrm{CW})$ ). When the sample was controlled for age, sex and both age and sex, as well as the participation in physical activity, the openskilled group continued to demonstrate significantly better attention and inhibition skills as well as showing better visual scanning and cognitive flexibility (Trail Making Test B) when compared to the other participant groups. Previous research has found positive links between physical activity participation, irrespective of the form, and better Stroop [8] and Trail Making Test B scores in older adults [4]; the finding of better inhibition 


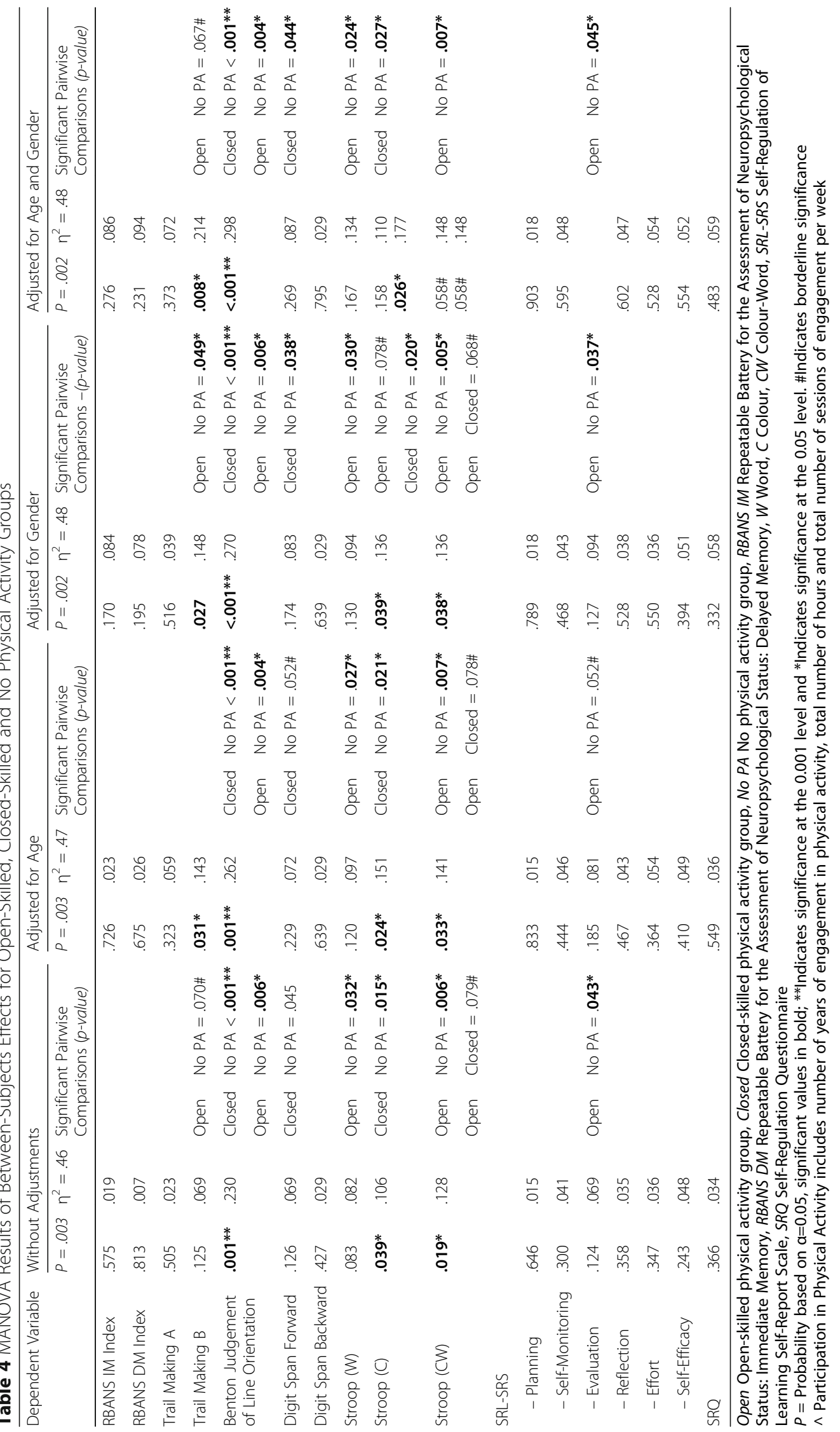


Table 5 MANCOVA Results of Between-Subjects Effects for Open-Skilled and Closed-Skilled Physical Activity Groups

\begin{tabular}{|c|c|c|}
\hline \multirow[t]{2}{*}{ Dependent Variable } & \multicolumn{2}{|c|}{ Adjusted for Age, Sex and ${ }^{\circledR}$ Participation in Physical Activity } \\
\hline & $P=.624$ & $\eta^{2}=.57$ \\
\hline RBANS IM Index & .373 & .200 \\
\hline RBANS DM Index & .149 & .279 \\
\hline Trail Making A & .758 & .111 \\
\hline Trail Making B & $.044^{*}$ & .361 \\
\hline Benton Judgement of Line Orientation & .473 & .175 \\
\hline Digit Span Forward & .790 & .103 \\
\hline Digit Span Backward & .306 & .219 \\
\hline Stroop $(W)$ & $.019 *$ & .408 \\
\hline Stroop (C) & $.045^{*}$ & .360 \\
\hline Stroop (CW) & .181 & .264 \\
\hline \multicolumn{3}{|l|}{ SRL-SRS } \\
\hline Planning & .960 & .050 \\
\hline Self-Monitoring & .103 & .306 \\
\hline Evaluation & .398 & .194 \\
\hline Reflection & .930 & .063 \\
\hline Effort & .283 & .227 \\
\hline Self-Efficacy & .657 & .134 \\
\hline SRQ & $.052 \#$ & .351 \\
\hline
\end{tabular}

$P=$ Probability based on $a=0.05$, significant values in bold; *Indicates significance at the 0.05 level. \#Indicates borderline significance

@ Participation in Physical Activity includes number of years of engagement in physical activity, total number of hours and total number of sessions of engagement per week

RBANS IM Repeatable Battery for the Assessment of Neuropsychological Status: Immediate Memory, RBANS DM Repeatable Battery for the Assessment of Neuropsychological Status: Delayed Memory, (W) Word, (C) Colour, (CW) Colour-Word, SRL-SRS Self-Regulation of Learning Self-Report Scale, SRQ Self-Regulation Questionnaire

ability in the open-skilled group mirrors the results of studies of younger populations $[37-39,42]$ and those of Huang et al.'s [17] study of older adults, which indicated that engagement in open-skilled exercise types was associated with greater neural efficiency for tasks that demanded interference control. Thus, the strength of the open-skilled physical activity group's scores for Stroop (CW) and in the Trail Making Test B may be explained by the theory that more cognitively demanding tasks, such as open-skilled physical activity, may result in better inhibition and cognitive flexibility in older adults $[10,12,17,64]$. However, further investigation of this theory is necessary to confirm these benefits.

Additionally, in this study, closed-skilled physical activity was significantly associated with better selective attention ability (Stroop $(\mathrm{C})$ ) and better visuospatial perception (Benton Judgement of Line Orientation). These findings are consistent with previous research that has demonstrated positive associations between the overall level of physical activity engagement by older adults and both attention skills $[7,8,65]$ and visuospatial perception [66]. Nevertheless, it is not clear why the closed-skilled group outperformed the open-skilled group in these specific areas as previous research has found the opposite [31, 67].
As a result, our second hypothesis was not supported. It is possible that these results are due to the particular types of closed-skilled physical activity in the sample as research has suggested that there may be selectively beneficial effects of physical activity on cognitive function depending on the inherent qualities of the particular activity type [17]. In our sample, in addition to swimming, which demands attention to specific positions of the arms, legs, head, and torso for greater swimming performance [32], one of the most common forms of closed-skilled physical activity was Tai Chi. This martial art is understood to be beneficial for cognitive function $[68,69]$ including attention [70] and visuospatial processing owing to the task demands of learning choreographed sequences of movements [68].

In partial support of our third hypothesis, increased number of hours of physical activity in the participant sample was positively associated with visuospatial perception, working memory, selective attention, and inhibition ability, while an increased number of years of physical activity engagement and physical activity sessions per week was positively associated with visuospatial perception and selective attention ability. In addition to further supporting the benefits of greater 
frequency and intensity of physical activity for cognitive functions in older adults $[3,71]$, these findings may also indicate that participants who engaged in more frequent physical activity had increased fitness levels, which has in itself been shown to benefit cognitive function [72, 73]. Furthermore, previous research has also found there to be a dose-response relationship between moderate-tovigorous-intensity physical activity and better cognitive function ability in older adults [35, 71]. The present study's results indicate that hours of physical activity engagement had a particularly strong impact on cognitive function scores compared with the other measures of physical activity intensity and frequency in this study. However, further investigation as to why this was the case, and reasons for why not more of the assessment results, including all self-regulation measures, were affected by physical activity levels of intensity and frequency remains necessary.

While this study addressed a considerable range of cognitive function indicators, it did not find significant correlations between physical activity type or frequency of participation across a number of key cognitive functions. Notably, no significant effects were found for immediate and delayed memory. Although some studies report benefits to memory from physical activity $[2,7,8$, $11]$, others have similarly inconclusive results $[63,74]$. For example, while 16 studies included in a review by Smith et al. [63] determined there to be modest effects to memory from aerobic exercise, the twelve studies looking specifically at the impact on working memory ability found no benefits. Nevertheless, there was one significant finding in the present study showing correlations between hours of physical activity participation and working memory. Chang et al. [75] also found better working memory to be associated with higher physical activity levels. However, unlike our study, which categorised individual physical activity patterns, physical activity levels were measured as a combined score of intensity, duration, and frequency. Therefore, it does not help to explain why working memory in our study was only significantly correlated with the number of hours of physical activity per week but not sessions per week or years or participation. Further research may be able to determine whether physical activity intensity has a stronger impact on working memory function in older adults when compared to the frequency of physical activity.

The only significant finding for self-regulation ability in this study was identified in the SRL-SRS (Evaluation). Analysis of between-group differences showed better results for the open-skilled group when compared with the no-physical activity group. There is limited evidence in previous literature to explain this finding. Nevertheless, it may be the case that the open-skilled group employed more successful metacognitive strategies by using evaluative skills in their behaviour. This might be explained by the specific task demands of open-skilled physical activity. For example, golf, one of the most commonly engaged in forms of open-skilled physical activity in the study sample, requires participants to consistently evaluate the changing environment of the game and consequently make numerous conscious adjustments to their movements [76]. However, it is not clear why no other self-regulation ability was significant for either the open-skilled or closed-skilled group. Therefore, our study has not determined there to be overall significant effects on self-regulation ability in older adults as a result of physical activity. It is possible that administering two self-regulation surveys towards the end of the assessment session, and in addition to the five other cognitive assessments, may have placed too much cognitive demand on participants and caused participant burden [48]. As a result, self-regulation measures may have been affected. Future investigation should consider strategies for administering multiple assessments while avoiding the likelihood of participant fatigue to prevent possible influence on assessments.

There were several limitations to acknowledge in our study. Firstly, to fulfil the inclusion criteria, participants self-reported information regarding their cognitive and physical health. As a result, this study can only assume that the information provided was accurate. As demonstrated in other studies [17, 30, 44], further investigation of this research area should require participants to complete a standardised cognitive assessment, such as the Mini-Mental State Examination (MMSE) [77], prior to data collection to screen participants' cognition. Because our study did not do this, cognitive function measures might have been negatively impacted as it was not possible to exclude participants who may have had mild cognitive impairments or other neurological conditions. Comprehensive screening of participants' physical health and fitness levels would also allow for a more detailed analysis of the true impact of physical activity types and intensity. Implementing these screening methods would allow for improved certainty of cognitive and fitness level homogeneity in the sample, thus increasing the validity of findings. This study did not investigate the effects of other personal factors such as schooling and type of job. Cognitive function may be affected by these factors other than the engagement of physical activity.

Moreover, as this study is a cross-sectional analysis, conclusions of causality between open-skilled and closed-skilled physical activity and cognitive function cannot be adequately determined from these results. The purpose of this study has been to provide additional data to the currently limited body of knowledge of this research area. However, further research, which establishes greater cause and effect probability by embarking 
on good quality intervention studies, using larger sample sizes and controlling for the personal factors and the level of physical activity participation [2,78], is required. This type of research design is necessary in order to properly understand the benefits of different physical activity types on cognitive function ability in older adults.

\section{Conclusions}

In summary, this preliminary study suggests that, in accordance with previous research, physical activity may have selectively beneficial effects on cognitive function $[17,41]$. Similar to the findings of Dai et al. [30], Huang et al. [17] and Guo et al. [44], results show that physical activity, regardless of being open- or closed-skilled, provides benefits for older adults' cognitive function ability when compared with no physical activity participation, with some potential additional advantages provided as a result of open-skilled physical activity engagement for selected cognitive processes. In our study, open-skilled physical activity was associated with better inhibition, visual tracking, and cognitive flexibility while closedskilled physical activity was associated with better selective attention and visuospatial perception. However, the majority of self-regulation ability was not significantly influenced by open- or closed-skilled physical activity in this study. Importantly, physical activity intensity and frequency were significantly correlated with a range of cognitive functions. Although much further investigation is required for a thorough understanding of this area, this study contributes important findings of the benefits of both open- and closed-skilled physical activity participation by older adults for a range of cognitive function measures.

\section{Abbreviations}

RBANS: Repeatable Battery for the Assessment of Neuropsychological Status; SRL-SRS: Self-Regulation of Learning Self-Report Scale; SRQ: Self-Regulation Questionnaire; Stroop (C): Stroop (Colour); Stroop (CW): Stroop (ColourWord); Stroop (W): Stroop (Word)

\section{Acknowledgements}

The authors would like to thank all the Ethical Committee for approving ethical clearance. We would like also to thank data collectors and study participants.

\section{Authors' contributions}

$\mathrm{MI}, \mathrm{NT}, \mathrm{CCHC}$, and KPYL were involved in the study design. MI, NT, and KPYL involved in data collection and supervision. $\mathrm{Ml}$ and $\mathrm{KL}$ completed the data processing and analysis. MI, NT, CCHC, and KPYL interpreted the data as well as drafted the manuscript. All the authors have critically reviewed the manuscript read and approved the final manuscript.

\section{Funding}

The authors declare that there is no funding source.

\section{Availability of data and materials}

The datasets used and/or analyzed during the current study are available from the corresponding author on reasonable request.

\section{Ethics approval and consent to participate}

The study was granted ethical approval from the Western Sydney University Human Ethics Committee (H11724).

The participants were provided with an information sheet and the study was explained to them verbally, providing an opportunity for them to discuss any concerns prior to providing written consent. Informed written consent was obtained for all participants before the start of the study. Confidentiality of information was maintained throughout the study.

Consent for publication

Not applicable.

\section{Competing interests}

All authors declare no potential conflicts of interest with respect to the research, authorship, and/or publication of this article.

\section{Author details}

${ }^{1}$ School of Health Sciences, Western Sydney University, Locked Bag 1797, Penrith, NSW 2751, Australia. ${ }^{2}$ Translation Health Research Institute, Western Sydney University, Locked Bag 1797, Penrith, NSW 2751, Australia. ${ }^{3}$ Department of Rehabilitation Sciences, The Hong Kong Polytechnic University, Hung Hom, Hong Kong. ${ }^{4}$ University Research Facility in Behavioural and Systems Neuroscience, The Hong Kong Polytechnic University, Hung Hom, Hong Kong.

Received: 24 March 2020 Accepted: 15 June 2020

Published online: 02 July 2020

\section{References}

1. United Nations: World population ageing 2009. In. Edited by Division DoEaSAP; 2009.

2. van Uffelen JG, Chinapaw MJ, Hopman-Rock M, van Mechelen W. The effects of exercise on cognition in older adults with and without cognitive decline: a systematic review. Clin J Sport Med. 2008;18(6):486-500.

3. Colcombe $S$, Kramer AF. Fitness effects on the cognitive function of older adults. Psychol Sci. 2003;14(2):125-30.

4. Benedict C, Brooks SJ, Kullberg J, Nordenskjold R, Burgos J, Le Greves M, Kilander L, Larsson EM, Johansson L, Ahlstrom H, et al. Association between physical activity and brain health in older adults. Neurobiol Aging. 2013; 34(1):83-90.

5. Erickson K, Prakash R, Voss M, Chaddock L, Hu L, Morris K, White SM, Wójcicki TR, McAuley E, Kramer AF. Aerobic fitness is associated with hippocampal volume in elderly humans. Hippocampus. 2009;19(10):1030-9.

6. Niemann C, Godde B, Staudinger UM, Voelcker-Rehage C. Exercise-induced changes in basal ganglia volume and cognition in older adults. Neuroscience. 2014;281:147-63.

7. Candela F, Zucchetti G, Magistro D, Rabaglietti E. The effects of a physical activity program and a cognitive training program on the long-term memory and selective attention of older adults: a comparative study. Act Adapt Aging. 2015;39(1):77-91.

8. Guiney $H$, Machado L. Benefits of regular aerobic exercise for executive functioning in healthy populations. Psychon Bull Rev. 2013;20(1):73-86.

9. Hillman C, Erickson K, Kramer A. Be smart, exercise your heart: exercise effects on brain and cognition. Nat Rev Neurosci. 2008;9(1):58-65.

10. Mueller AE, Raymond N, Yochim BP. Cognitive activity engagement predicts future memory and executive functioning in older adults. Act Adapt Aging. 2013;37(3):251-64

11. Nishiguchi S, Yamada M, Tanigawa T, Sekiyama K, Kawagoe T, Suzuki M, Yoshikawa S, Abe N, Otsuka Y, Nakai R, et al. A 12-week physical and cognitive exercise program can improve cognitive function and neural efficiency in community-dwelling older adults: a randomized controlled trial. J Am Geriatr Soc. 2015;63(7):1355-63.

12. Sánchez-Horcajo R, Llamas-Alonso J, Cimadevilla J. Practice of aerobic sports is associated with better spatial memory in adults and older men. Exp Aging Res. 2015;41(2):193-203.

13. Voss MW, Nagamatsu LS, Liu-Ambrose T, Kramer AF. Exercise, brain, and cognition across the life span. J Appl Physiol. 2011;111(5):1505-13.

14. Lista I, Sorrentino G. Biological mechanisms of physical activity in preventing cognitive decline. Cell Mol Neurobiol. 2010;30(4):493-503.

15. Meeusen R. Exercise, nutrition and the brain. Sports Med. 2014;44(1):47-56. 
16. Palta P, Sharrett AR, Deal JA, Evenson KR, Gabriel KP, Folsom AR, Gross AL, Windham BG, Knopman D, Mosley TH, et al. Leisure-time physical activity sustained since midlife and preservation of cognitive function: the atherosclerosis risk in communities study. Alzheimers Dement. 2019;15(2): 273-81.

17. Huang C, Lin P, Hung C, Chang Y, Hung T. Type of physical exercise and inhibitory function in older adults: an event-related potential study. Psychol Sport Exerc. 2014;15(2):205-11.

18. Miyake A, Friedman NP. The nature and Organization of Individual Differences in executive functions: four general conclusions. Curr Dir Psychol Sci. 2012;21(1):8-14.

19. Chan RC, Shum D, Toulopoulou T, Chen EY. Assessment of executive functions: review of instruments and identification of critical issues. Arch Clin Neuropsychol. 2008;23(2):201-16.

20. Ikeda Y, Ogawa N, Yoshiura K, Han G, Maruta M, Hotta M, Tabira T. Instrumental Activities of Daily Living: The Processes Involved in and Performance of These Activities by Japanese Community-Dwelling Older Adults with Subjective Memory Complaints. Int J Environ Res Public Health. 2019:16(14):2617 2019, 16(14):2617.

21. Contador I, Fernández-Calvo B, Rueda-Revé L, Olazarán J, Bermejo-Pareja F. Characterizing functional alterations in instrumental activities of daily living using latent class analysis: a population-based study (NEDICES). Aging Ment Health. 2020;24(1):41-8

22. Osaka M, Yaoi K, Otsuka Y, Katsuhara M, Osaka N. Practice on conflict tasks promotes executive function of working memory in the elderly. Behav Brain Res. 2012;233(1):90-8.

23. Martyr A, Clare L. Executive function and activities of daily living in Alzheimer's disease: a correlational meta-analysis. Dement Geriatr Cogn Disord. 2012;33(2-3):189-203.

24. Fujita K. On conceptualizing self-control as more than the effortful inhibition of impulses. Personal Soc Psychol Rev. 2011;15(4):352-66.

25. Brittain D, Dinger M, Classen J, Camero Garcia M, Sage L, Han J. Perceived barriers, coping strategies, and self-regulatory efficacy to cope: an examination of sufficiently and insufficiently physically active middle-aged and older women. Act Adapt Aging. 2012;36(1):11-28.

26. Legault L, Inzlicht M. Self-determination, self-regulation, and the brain: autonomy improves performance by enhancing neuroaffective responsiveness to self-regulation failure. J Pers Soc Psychol. 2013;105(1):123-38.

27. Hanif A, Ferrey AE, Frischen A, Pozzobon K, Eastwood JD, Smilek D, Fenske MJ. Manipulations of attention enhance self-regulation. Acta Psychol. 2011

28. Wrosch C, Dunne E, Scheier M, Schulz R. Self-regulation of common agerelated challenges: benefits for older adults' psychological and physical health. J Behav Med. 2006;29(3):299-306.

29. Wang $\mathrm{CH}$, Chang CC, Liang YM, Shih CM, Chiu WS, Tseng P, Hung DL, Tzeng OJ, Muggleton NG, Juan CH. Open vs. closed skill sports and the modulation of inhibitory control. PLoS One. 2013;8(2):e55773.

30. Dai CT, Chang YK, Huang CJ, Hung TM. Exercise mode and executive function in older adults: an ERP study of task-switching. Brain Cogn. 2013; 83(2):153-62.

31. Wang $\mathrm{CH}$, Chang CC, Liang YM, Shih CM, Chiu WS, Tseng P, Hung DL, Tzeng OJ, Muggleton NG, Juan CH. Open vs. closed skill sports and the modulation of inhibitory control. PLoS One. 2013;8(2):1-10.

32. Formosa DP, Sayers MGL, Burkett B. Quantifying stroke coordination during the breathing action in front-crawl swimming using an instantaneous net drag force profile. J Sports Sci. 2014:1-9.

33. Feter N, Spanevello RM, Soares MSP, Spohr L, Pedra NS, Bona NP, Freitas MP, Gonzales NG, Ito LGMS, Stefanello FM, et al. How does physical activity and different models of exercise training affect oxidative parameters and memory? Physiol Behav. 2019;201:42-52.

34. Hammond AG, Murphy EM, Silverman BM, Bernas RS, Nardi D. No environmental context-dependent effect, but interference, of physical activity on object location memory. Cogn Process. 2019;20(1):31-43.

35. Zhu GW, Wadley JV, Howard NV, Hutto PB, Blair PS, Hooker PS. Objectively measured physical activity and cognitive function in older adults. Med Sci Sports Exerc. 2017:49(1):47-53.

36. Gu Q, Zou L, Loprinzi PD, Quan M, Huang T. Effects of open versus closed skill exercise on cognitive function: a systematic review. Front Psychol. 2019; 10:1707.

37. Crova C, Struzzolino I, Marchetti R, Masci I, Vannozzi G, Forte R, Pesce C. Cognitively challenging physical activity benefits executive function in overweight children. J Sports Sci. 2013:1-11.
38. Pan C-Y, Chu C-H, Tsai C-L, Lo S-Y, Cheng Y-W, Liu Y-J. A racket-sport intervention improves behavioral and cognitive performance in children with attention-deficit/hyperactivity disorder. Res Dev Disabil. 2016;57:1-10.

39. Tsai $C L$. The effectiveness of exercise intervention on inhibitory control in children with developmental coordination disorder: using a visuospatial attention paradigm as a model. Res Dev Disabil. 2009;30(6):1268-80.

40. Di Russo F, Bultrini A, Brunelli S, Delussu AS, Polidori L, Taddei F, Traballesi $M$, Spinelli D. Benefits of sports participation for executive function in disabled athletes. J Neurotrauma. 2010;27(12):2309-19.

41. Nuri L, Shadmehr A, Ghotbi N, Attarbashi Moghadam B. Reaction time and anticipatory skill of athletes in open and closed skill-dominated sport. Eur J Sport Sci. 2013;13(5):431-6.

42. Wang $\mathrm{CH}$, Chang CC, Liang YM, Shih $\mathrm{CM}$, Muggleton NG, Juan $\mathrm{CH}$. Temporal preparation in athletes: a comparison of tennis players and swimmers with sedentary controls. J Mot Behav. 2013;45(1):55-63.

43. Taddei F, Bultrini A, Spinelli D, Di Russo F. Neural correlates of attentional and executive processing in middle-age fencers. Med Sci Sports Exerc. 2012; 44(6):1057-66

44. Guo W, Wang B, Lu Y, Zhu Q, Shi Z, Ren J. The relationship between different exercise modes and visuospatial working memory in older adults: a cross-sectional study. PeerJ. 2016:4:e2254.

45. Arnautovska U, Fleig L, O'Callaghan F, Hamilton K. A longitudinal investigation of older adults' physical activity: testing an integrated dualprocess model. Psychol Health. 2017;32(2):166-85.

46. Janssen I, Dugan S, Karavolos K, Lynch E, Powell L. Correlates of 15-year maintenance of physical activity in middle-aged women. Official J Int Soc Behav Med. 2014:21(3):511-8.

47. Olson E, McAuley E. Impact of a brief intervention on self-regulation, selfefficacy and physical activity in older adults with type 2 diabetes. J Behav Med. 2015:38(6):886-98.

48. Umstattd MR, Wilcox S, Saunders R, Watkins K, Dowda M. Self-regulation and physical activity: the relationship in older adults. (Clinical report). Am J Health Behav. 2008;32(2):115.

49. Warner LM, Wolff JK, Ziegelmann JP, Schwarzer R, Wurm S. Revisiting selfregulatory techniques to promote physical activity in older adults: nullfindings from a randomised controlled trial. Psychol Health. 2016:1-21.

50. Winett RA, Williams DM, Davy BM. Initiating and maintaining resistance training in older adults: a social cognitive theory-based approach. $\mathrm{Br} J$ Sports Med. 2009;43(2):114.

51. Karantzoulis S, Novitski J, Gold M, Randolph C. The repeatable battery for the assessment of neuropsychological status (RBANS): utility in detection and characterization of mild cognitive impairment due to Alzheimer's disease. Arch Clin Neuropsychol. 2013;28(8):837-44.

52. Misdraji EL, Gass CS. The trail making test and its neurobehavioral components. J Clin Exp Neuropsychol. 2010;32(2):159-63.

53. Sánchez-Cubillo I, PerianEz JA, Adrover-Roig D, RodríGuez-Sánchez JM, RiosLago M, Tirapu J, Barcelo F. Construct validity of the trail making test: role of task-switching, working memory, inhibition/interference control, and visuomotor abilities. J Int Neuropsychol Soc. 2009;15(3):438-50.

54. Spencer RJ, Wendell CR, Giggey PP, Seliger SL, Katzel LI, Waldstein SR. Judgment of line orientation: an examination of eight short forms. J Clin Exp Neuropsychol. 2013;35(2):160-6.

55. Calamia M, Markon K, Denburg NL, Tranel D. Developing a short form of Benton's judgment of line orientation test: an item response theory approach. Clin Neuropsychol. 2011;25(4):670-84.

56. Wechsler D: Wechsler adult intelligence scale: administration and scoring manual 3 edn. Sidcup: Psychological Corporation; 1997.

57. Jones G, Macken B. Questioning short-term memory and its measurement: why digit span measures long-term associative learning. Cognition. 2015:144:1-13.

58. Seo EH, Lee DY, Choo IH, Kim SG, Kim KW, Youn JC, Jhoo JH, Woo Jl. Normative study of the Stroop color and word test in an educationally diverse elderly population. Int J Geriatr Psychiatry. 2008;23(10):1020-7.

59. Jakesova J, Gavora P, Kalenda J. Self-regulation of behaviour: students versus other adults. Int J Educ Psychol. 2016:5(1):56-79.

60. Toering T, Elferink-Gemser MT, Jonker L, van Heuvelen MJG, Visscher C. Measuring self-regulation in a learning context: reliability and validity of the self-regulation of learning self-report scale (SRL-SRS). Int I Sport Exerc Psychol. 2012;10(1):24-38.

61. Bixby W, Spalding T, Haufler A, Deeny S, Mahlow P, Zimmerman J, Hatfield $B$. The unique relation of physical activity to executive function in older men and women. Med Sci Sports Exerc. 2007;39(8):1408-16. 
62. Eggermont LHP, Milberg WP, Lipsitz LA, Scherder EJA, Leveille SG. Physical activity and executive function in aging: the MOBILIZE Boston study. J Am Geriatr Soc. 2009;57(10):1750-6.

63. Smith PJ, Blumenthal JA, Hoffman BM, Cooper H, Strauman TA, WelshBohmer K, Browndyke JN, Sherwood A. Aerobic exercise and neurocognitive performance: a meta-analytic review of randomized controlled trials. Psychosom Med. 2010;72(3):239-52.

64. Tranter LJ, Koutstaal W. Age and flexible thinking: an experimental demonstration of the beneficial effects of increased cognitively stimulating activity on fluid intelligence in healthy older adults. Aging Neuropsychol Cognit. 2008;15(2):184-207.

65. Liu-Ambrose T, Nagamatsu LS, Graf P, Beattie BL, Ashe MC, Handy TC: Resistance training and executive functions: a 12-month randomized controlled trial. (Clinical report). Arch Intern Med 2010, 170(2):170.

66. Wang C-H, Tsai C-L. Physical activity is associated with greater Visuospatial cognitive functioning regardless of the level of cognitive load in elderly adults. J Sport Exerc Psychol. 2016;38(1):69.

67. Voss M, Kramer A, Basak C, Prakash R, Roberts B. Are expert athletes 'expert' in the cognitive laboratory? A meta-analytic review of cognition and sport expertise. Appl Cogn Psychol. 2010;24(6):812.

68. Wayne PM, Walsh JN, Taylor-piliae RE, Wells RE, Papp KV, Donovan NJ, Yeh GY. Effect of tai chi on cognitive performance in older adults: systematic review and meta-analysis. J Am Geriatr Soc. 2014;62(1):25-39.

69. Zheng G, Liu F, Li S, Huang M, Tao J, Chen L. Tai chi and the protection of cognitive ability: a systematic review of prospective studies in healthy adults: a systematic review of prospective studies in healthy adults. Am J Prev Med. 2015;49(1):89-97.

70. Kim T, Pascual-Leone J, Johnson J, Tamim H. The mental-attention tai chi effect with older adults. BMC Psychology. 2016:4.

71. Kerr J, Marshall SJ, Patterson RE, Marinac CR, Natarajan L, Rosenberg D, Wasilenko K, Crist K. Objectively measured physical activity is related to cognitive function in older adults. J Am Geriatr Soc. 2013;61(11):1927-31.

72. Boucard G, Albinet C, Bugaiska A, Bouquet C, Clarys D, Audiffren M. Impact of physical activity on executive functions in aging: a selective effect on inhibition among old adults. J Sport Exerc Psychol. 2012:34(6):808.

73. Chu C-H, Chen A-G, Hung T-M, Chang Y-K, Wang C-C. Exercise and fitness modulate cognitive function in older adults. Psychol Aging. 2015:30(4):842-8.

74. Frederiksen $\mathrm{KS}$, Verdelho A, Madureira S, Bäzner $\mathrm{H}, \mathrm{O}^{\prime}$ Brien JT, Fazekas F, Scheltens $P$, Schmidt R, Wallin A, Wahlund LO, et al. Physical activity in the elderly is associated with improved executive function and processing speed: the LADIS study. Int J Geriatr Psychiatry. 2015;30(7):744-50.

75. Chang Y-K, Huang C-J, Chen K-F, Hung T-M. Physical activity and working memory in healthy older adults: an ERP study. Psychophysiology. 2013; 50(11):1174-82

76. Toner J, Moran A. The effects of conscious processing on golf putting proficiency and kinematics. J Sports Sci. 2011;29(7):673.

77. Folstein MF, Folstein SE, PR MH. "Mini-mental state": a practical method for grading the cognitive state of patients for the clinician. J Psychiatr Res. 1975;12(3):189-98.

78. Snowden M, Steinman L, Mochan K, Grodstein F, Prohaska TR, Thurman DJ, Brown DR, Laditka JN, Soares J, Zweiback DJ, et al. Effect of exercise on cognitive performance in community-dwelling older adults: review of intervention trials and recommendations for public health practice and research. J Am Geriatr Soc. 2011;59(4):704-16.

\section{Publisher's Note}

Springer Nature remains neutral with regard to jurisdictional claims in published maps and institutional affiliations.

Ready to submit your research? Choose BMC and benefit from:

- fast, convenient online submission

- thorough peer review by experienced researchers in your field

- rapid publication on acceptance

- support for research data, including large and complex data types

- gold Open Access which fosters wider collaboration and increased citations

- maximum visibility for your research: over $100 \mathrm{M}$ website views per year

At BMC, research is always in progress.

Learn more biomedcentral.com/submissions 